\title{
Three Vessel Coronary Disease
}

National Cancer Institute

\section{Source}

National Cancer Institute. Three Vessel Coronary Disease. NCI Thesaurus. Code C100020.

There was greater than or equal to $50 \%$ stenosis (reduction in cross-sectional area) in three coronary arteries (or greater than or equal to 50\% stenosis in the left main coronary artery and greater than or equal to $50 \%$ stenosis in the right coronary artery). (ACC) 